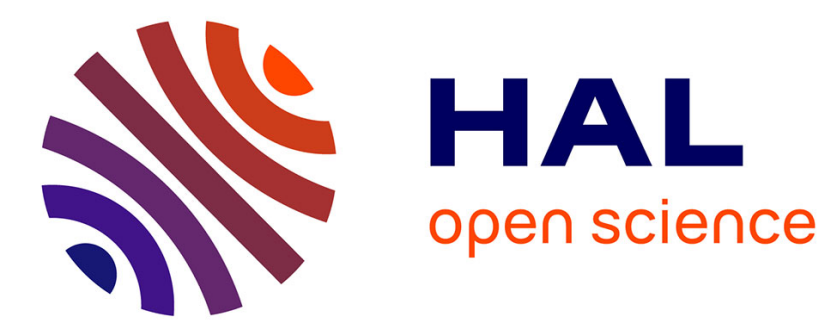

\title{
The gasification reactivity of high-heating-rate chars in single and mixed atmospheres of $\mathrm{H} 2 \mathrm{O}$ and $\mathrm{CO} 2$
}

Chamseddine Guizani, Francisco Javier Escudero Sanz, Sylvain Salvador

\section{To cite this version:}

Chamseddine Guizani, Francisco Javier Escudero Sanz, Sylvain Salvador. The gasification reactivity of high-heating-rate chars in single and mixed atmospheres of H2O and CO2. Fuel, 2013, 108, pp.812823. 10.1016/j.fuel.2013.02.027 . hal-01688113

\section{HAL Id: hal-01688113 https://hal.science/hal-01688113}

Submitted on 12 Mar 2018

HAL is a multi-disciplinary open access archive for the deposit and dissemination of scientific research documents, whether they are published or not. The documents may come from teaching and research institutions in France or abroad, or from public or private research centers.
L'archive ouverte pluridisciplinaire HAL, est destinée au dépôt et à la diffusion de documents scientifiques de niveau recherche, publiés ou non, émanant des établissements d'enseignement et de recherche français ou étrangers, des laboratoires publics ou privés. 


\title{
The gasification reactivity of high-heating-rate chars in single and mixed atmospheres of $\mathrm{H}_{2} \mathrm{O}$ and $\mathrm{CO}_{2}$
}

\author{
C. Guizani*, F.J. Escudero Sanz, S. Salvador \\ RAPSODEE, Mines Albi, Route de Teillet, 81013 ALBI CT Cedex 09, France
}

Keywords:

Biomass char

Gasification

$\mathrm{H}_{2} \mathrm{O}$ and $\mathrm{CO}_{2}$ mixed atmospheres

Kinetics

\begin{abstract}
A B S T R A C T
Gasification reactivity of high heating rate chars (HHR chars) in steam, carbon dioxide and their mix tures was investigated in a new macro TG experimental device. The higher reactivity of the HHR chars was highlighted by a comparison with reference chars prepared at a low heating rate (LHR chars). It was found that the char reactivity in a mixed atmosphere of steam and carbon dioxide can be expressed as the sum of the individual reactivities obtained in single atmosphere gasification experiments. This result was not dependent on the pyrolysis heating rate. In addition, gas alternation gasification experi ments for both HHR chars and LHR chars showed that gasifying the char with $\mathrm{CO}_{2}$ up to $30 \%$ of con version does not affect its reactivity to $\mathrm{H}_{2} \mathrm{O}$. Altogether, the results tend to indicate that the two reactant gases $\mathrm{H}_{2} \mathrm{O}$ and $\mathrm{CO}_{2}$ react on separate active sites when mixed atmospheres are used, and that $\mathrm{CO}_{2}$ does not affect the char structure to favor or inhibit the char $\mathrm{H}_{2} \mathrm{O}$ gasification reaction.
\end{abstract}

\section{Introduction}

Both industrialized and developing countries are today intensi fying their work on the development of renewable energies. This increasing interest is a response to the unavoidable depletion of fossil fuels and to continuous and alarming environmental prob lems, especially global warming. Global warming is a direct conse quence of the increasing concentration of greenhouse gases in the atmosphere, particularly $\mathrm{CO}_{2}$, whose concentration has risen dras tically since the industrial revolution [1].

The conversion of biomass to energy is considered to be a path way towards clean and renewable energy production, because of the availability of the resource and the carbon neutral feature of the thermochemical processes [2].

Among these thermochemical processes, biomass gasification is gaining further interest as it allows the production of clean fuel gases (e.g. $\mathrm{H}_{2}, \mathrm{CO}, \mathrm{CH}_{4}$ ) that can be used either to produce

\footnotetext{
* Corresponding author. Tel.: +33 619572786.

E-mail address: cguizani@mines-albi.fr (C. Guizani).
}

electricity and heat or as an input stream to produce chemicals or transportation biofuels [3].

Biomass gasification can be processed with various gasifying re agents like air, steam or carbon dioxide [4]. Using carbon dioxide in such a process would provide a long term solution to mitigate its increasing concentration in the atmosphere. The $\mathrm{CO}_{2}$ will be then incorporated in a valorisation cycle for the production of market able fuels, rather than simply being captured and stored.

The biomass gasification reaction includes three main steps: pyrolysis, volatile matter reforming and char gasification. The char gasification reaction is considered to be the limiting step of the process because it is kinetically slow compared to the two other steps.

A huge amount of studies can be found in the literature, as well as very good reviews on char gasification in steam or carbon diox ide containing atmospheres [4 6]. Still, the majority of these stud ies do not tackle the issue of char gasification in mixed atmospheres; only a few do so, and these are performed mainly on coal char gasification.

Their conclusions differ from one study to another; some authors concluded that adding the carbon dioxide alongside the 
steam slows down the gasification reaction: (i) by inhibition and competition for the same carbon active sites [7 9]. For instance, in their work on coal char gasification, Robert and Harris mea sured the gasification reaction rate in single and mixed atmo sphere of $\mathrm{H}_{2} \mathrm{O}$ and $\mathrm{CO}_{2}$ in a thermogravimetric apparatus and concluded that the presence of $\mathrm{CO}_{2}$ reduces the rate of the $\mathrm{C}$ $\mathrm{H}_{2} \mathrm{O}$ reaction [7].

Others think that the two gases operate on separate active sites: (ii) by passive cooperation [10 12]. The work of Everson et al. de scribes this assertion well [11]. The authors studied the gasification reactions of coal chars in a TG apparatus with different atmosphere compositions and concluded that the char gasification reaction with mixtures of $\mathrm{CO}_{2}$ and $\mathrm{H}_{2} \mathrm{O}$ is best described by the sum of the single reaction rates. The same observation was made in the work of Chen et al. on sewage sludge char gasification in a fluid ized bed [13]. The authors again found that the reaction rate in a mixture of $\mathrm{CO}_{2}+\mathrm{H}_{2} \mathrm{O}$ is well represented by the sum of the individ ual reaction rates.

Other researchers think that there is a kind of (iii) synergy or active cooperation between the two gases that leads to an en hanced char reactivity [14,15]. For instance, Tagutchou [14] found that adding $\mathrm{CO}_{2}$ alongside steam leads to enhanced char reactivity which is superior to the sum of the individual reactivities obtained respectively with steam and carbon dioxide. A more detailed liter ature review and discussion is presented later in this paper as an approach for an extended experimental plan.

The different findings and conclusions in the literature make it difficult to draw a clear conclusion on the unfolding of the gasifica tion reaction in a mixed atmosphere of $\mathrm{H}_{2} \mathrm{O}$ and $\mathrm{CO}_{2}$. The present work was thus performed with the aim to further understand the reaction mechanisms of biomass gasification in mixed atmo spheres of steam and carbon dioxide.

\section{Materials and methods}

\subsection{Macro TG experimental device}

The new Macro TG experimental device (Fig. 1) consists of three major parts:

- The heating system, including a liquid $\mathrm{H}_{2} \mathrm{O}$ evaporator, a gas preheater and an electrically heated alumina reactor.

- The gas flow control system consisting of 3 mass flow meters/ controllers.

- The weighing system that comprises an electronic scale, a stand and a platinum basket.

The $2 \mathrm{~m}$ long, $75 \mathrm{~mm}$ i.d. alumina reactor is electrically heated. The temperatures of the three reactor zones (high, medium and low) are independently controlled to ensure good temperature homogeneity throughout the furnace.

Gas flow rates are controlled by means of mass flow meters/ controllers. Before entering the reaction zone, the reactant gases $\left(\mathrm{N}_{2}, \mathrm{CO}_{2}\right.$ and $\left.\mathrm{H}_{2} \mathrm{O}\right)$ are preheated up to the reactor temperature. When $\mathrm{H}_{2} \mathrm{O}$ is added in the gasification medium, the $\mathrm{H}_{2} \mathrm{O}$ + gas mix ture passes first through an electrically heated evaporator main tained at $180^{\circ} \mathrm{C}$ to vaporize the water. The reacting gas flow inside the reactor is laminar and flowing at an average velocity of $0.2 \mathrm{~m} / \mathrm{s}$.

The weighing system comprises a set of electronic scales with an accuracy of $\pm 0.1 \mathrm{mg}$, a metallic stand placed over the balance, on which are fixed three ceramic hollow tubes with a length of $1 \mathrm{~m}$ and a $2.4 \mathrm{~mm}$ external diameter. These ceramic tubes hold up a platinum basket with a $50 \mathrm{~mm}$ diameter, a solid bottom and a side wall made from a $500 \mu \mathrm{m}$ grid to allow the gas to pass through it. The biomass samples are placed into it and are then pyrolysed and gasified in the hot furnace.

The weighing system can be moved in the vertical direction using a crank handle. The platinum basket can hence be introduced into the hot furnace within less than $15 \mathrm{~s}$.

Altogether, the macro TG experimental device has the advan tage of being of a far greater experimental scale than conventional TG devices. This makes sample representativity better because an average result for several woodchips is obtained for each run. The wood chips or char particles are not ground as they use to be when the gasification was performed in a classic TG device. This is impor tant because the size reduction process leads to modifications in the structural and chemical composition, loss of fibrous texture and heterogeneous dispersion of catalytic minerals, which vary according to the biomass particle size range [16]. This would affect the biomass reactivity data, which may not be representative of the raw biomass. Moreover, the biomass particles are submitted to a thermal shock similar to that endured when they are introduced in a fluidized bed.

Finally, to our best knowledge, it is not possible to perform iso thermal gasification experiments in a classic TG device without preheating the char sample to the desired temperature over a con siderable time. This thermal treatment has an impact on the char reactivity. In fact, It has been widely demonstrated for several bio masses such as maize stalk, rice straw, cotton straw, rice husk, Bra zil Nut shells and eucalyptus that the char reactivity decreases with thermal treatment as a result of morphological modifications encompassing the evolution of the level and type of porosity and the average pore size [17 21]. The char structure becomes increas ingly condensed and ordered when increasing the heat treatment temperature and duration. This thermal annealing phenomenon would surely distort the real char reactivity data. On the contrary, in our case, the biomass sample is introduced into the reactor with in $15 \mathrm{~s}$. The pyrolysis takes less than $1 \mathrm{~min}$ to be fulfilled.

\subsection{Biomass feedstock and char preparation}

\subsubsection{Biomass feedstock}

The biomass feedstock (beech wood chips) was provided by a company called SPPS (France). The woodchips were firs sieved to select particles with a size ranging between 4 and $5 \mathrm{~mm}$ and a thickness of $12 \mathrm{~mm}$.

The size and thickness of biomass particles may greatly influ ence the rate of the gasification reaction if they impact on the heat and mass transfer inside the particle [6,22]. In a recent study $[23,14]$, the authors demonstrated that the gasification rate was not influenced when varying the char particle size in the range of $10.515 \mathrm{~mm}$. The influencing characteristic dimension was rather the particle thickness, as it slowed down the reaction rate by 1.6 times when it was increased from 1.5 to $6 \mathrm{~mm}$ for a constant size of $10.5 \mathrm{~mm}$. No differences were observed between thick nesses of 2.5 and $1.5 \mathrm{~mm}$, which suggests that the reaction is chemically controlled below a $2.5 \mathrm{~mm}$ particle thickness. On the basis of these observations and of the similarities between the raw biomasses used (beech wood chips) and between the experi mental devices (Macro TG), we performed the gasification reac tions with biomass and char particles having a size in the range of $45 \mathrm{~mm}$ and a thickness of about $12 \mathrm{~mm}$.

\subsubsection{Experimental procedure for char preparation and gasification}

A mass of wood chips of $0.81 \mathrm{~g}$ is introduced in the platinum basket; the biomass particles are spaced widely enough to avoid chemical and thermal interactions. After heating the reactor to the desired temperature, the weighing system is lifted up using the crank handle; the platinum basket containing the wood chips is introduced into the hot furnace in less than $15 \mathrm{~s}$. The biomass 


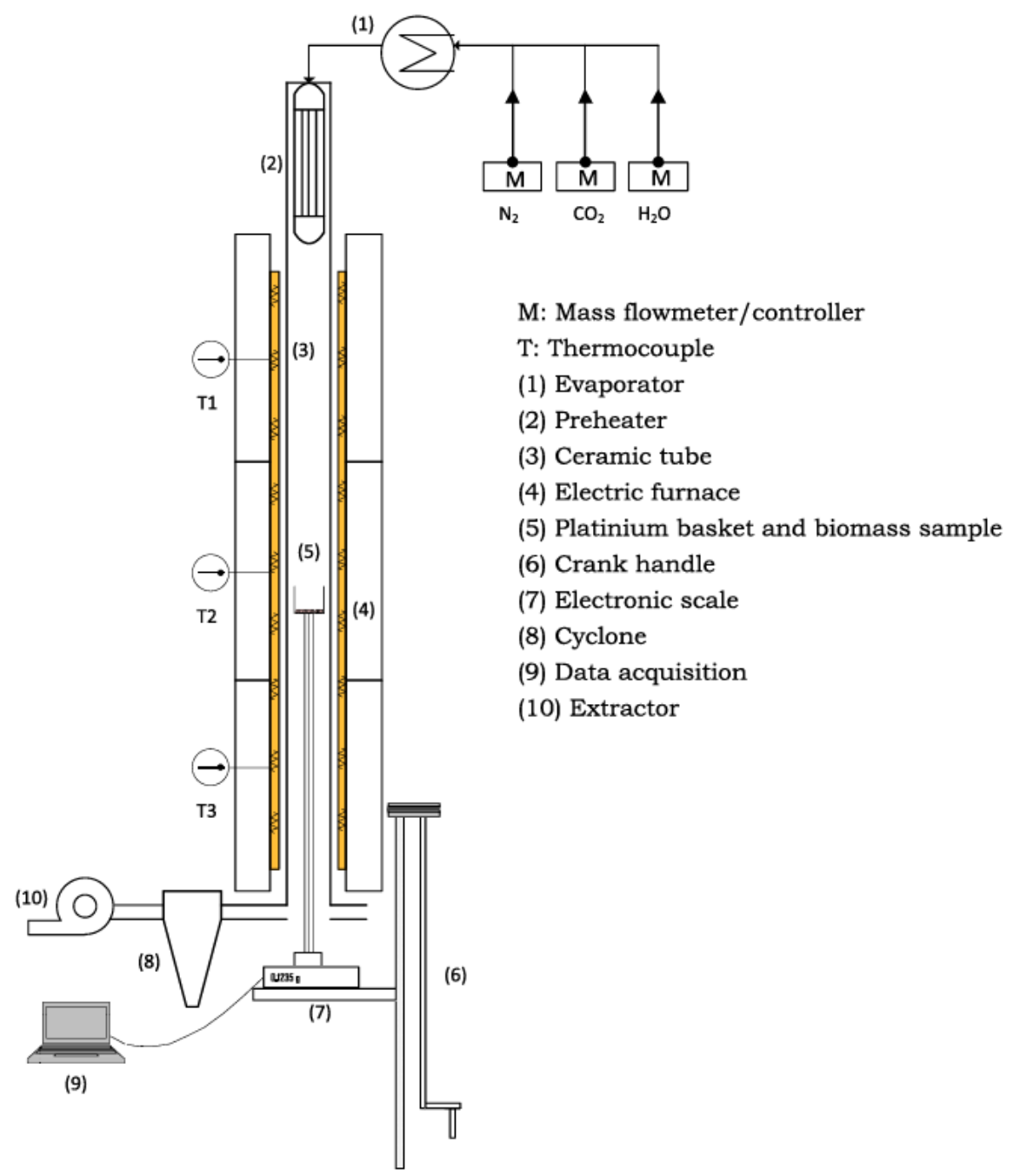

Fig. 1. Macro-TG experimental device scheme.

is firstly pyrolysed in a flow of nitrogen until reaching a constant mass, corresponding to the char. This procedure produces special chars prepared at a high heating rate which was estimated to be around $100 \mathrm{~K} / \mathrm{s}$ [24]. When the mass of char is stabilized, the dis played weight on the electronic scales is reinitialized to zero and the reactant gas flow is established, marking the beginning of the char gasification stage. When introducing the reacting gas $\left(\mathrm{CO}_{2}\right.$ or $\mathrm{H}_{2} \mathrm{O}$ ) alongside the nitrogen, we observe a flow deceleration ef fect (gas pressure on the platinum basket) on the force registered by the scales. This effect is corrected afterwards in the data pro cessing phase. The mass of char begins to decrease progressively until it reaches a plateau corresponding to the end of the experi ment. The weighing system is then moved downwards using the crank handle and the residual ashes are weighed after cooling. Fol lowing this procedure, we can obtain an accurate value for the mass of char that was converted during the gasification reaction.

The study focuses mainly on the gasification of biomass chars prepared at a high heating rate in the Macro TG device, as de scribed in the previous paragraph. However, in order to highlight the higher reactivity of these "HHR chars" (in terms of reactivity towards $\mathrm{H}_{2} \mathrm{O}$ and $\mathrm{CO}_{2}$ ), we also conducted gasification experiments with chars prepared at a low heating rate "LHR chars".

These LHR chars were obtained after a slow pyrolysis in a retort furnace with a heating rate of $5{ }^{\circ} \mathrm{C} / \mathrm{min}$ up to $550{ }^{\circ} \mathrm{C}$ and a residence time at the final temperature of $30 \mathrm{~min}$. The slow pyro lysis was performed under a nitrogen flow of $2 \mathrm{Nl} / \mathrm{min}$. The LHR char samples were then cooled to room temperature and stocked in a sealed recipient for gasification tests in the M TG device. With a low heating rate, the char yield was about $24.8 \%$, whereas it was much lower with a high heating rate. It decreased slightly when increasing the reaction temperature, from $9.89 \%$ at $850^{\circ} \mathrm{C}$ to $7.87 \%$ at $950^{\circ} \mathrm{C}$. These results were expected in view of previous studies on biomass pyrolysis $[25,19,4]$.

Table 1 lists the results of the proximate and ultimate analysis of the raw biomass wood chips, the LHR chars and the HHR chars obtained at three temperatures. The results are reported on a dry basis.

The ash content rose with an increase in the pyrolysis heating rate, due to lower char yields and little devolatilisation of the min eral species. One can note that the fuel nitrogen remained in the char. The concentrations of hydrogen and oxygen decreased with an increase in the temperature.

\subsubsection{Experimental conditions and data analysis method}

The gasification experiments were performed at atmospheric pressure with operating conditions similar to those encountered in fluidized bed gasifiers. The reactor temperature was in the range of $800950{ }^{\circ} \mathrm{C}$ and the gasifying medium partial pressure in the 
Table 1

Proximate and ultimate analysis of the biomass samples (dry basis).

\begin{tabular}{|c|c|c|c|c|c|c|c|}
\hline & \multicolumn{3}{|c|}{ Proximate analysis (\%) } & \multicolumn{4}{|c|}{ Ultimate analysis (\%) } \\
\hline & VM & Ash & FC & C & $\mathrm{H}$ & $\mathrm{O}$ & $\mathrm{N}$ \\
\hline Wood chips & 88.1 & 0.4 & 11.6 & 46.1 & 5.5 & 48.1 & 0.10 \\
\hline LHR-Char & 20.03 & 1.88 & 78.09 & 82.06 & 2.85 & 12.88 & 0.30 \\
\hline HHR-char $850^{\circ} \mathrm{C}$ & - & 3.75 & - & 83.51 & 0.86 & 11.60 & 0.28 \\
\hline HHR-char $900^{\circ} \mathrm{C}$ & - & 4.14 & - & 85.56 & 0.80 & 8.42 & 1.04 \\
\hline HHR-char $950^{\circ} \mathrm{C}$ & - & 4.15 & - & 85.83 & 0.91 & 8.07 & 1.05 \\
\hline
\end{tabular}

range of $0.10 .3 \mathrm{~atm}$. Table 2 gives the operating conditions for the different gasification experiments.

\subsubsection{Method of data analysis}

The normalized mass or conversion ratio ' $X$ ' during the gasifica tion reaction is calculated according to:

$X_{(t)} \frac{m_{(0)} m_{(t)}}{m_{(0)}} m_{(\text {ash })}$

where $m_{0}, m_{(t)}$ and $m_{\text {ash }}$ are respectively the initial mass of char, the mass at any time " $t$ " and the mass of the residual ash.

The gasification experiments were reproduced 25 times and showed a good repeatability with deviation less than $12 \%$, which is considered acceptable regarding the heterogeneity of the wood material. Mass loss data curves were firstly smoothed using a poly nomial least square function covering a fixed time period before and after each point. Precautions were taken for restoring smoothed data, with high fidelity to the experimental results. These data were then used to calculate the instantaneous reactivity of the char throughout the gasification.

Reactivity data were obtained following the next equation:

$R_{(X)} \quad \frac{1}{m_{(t)}} \frac{d m_{(t)}}{d t} \quad \frac{1}{1 \quad X_{(t)}} \frac{d X_{(t)}}{d t}$

The char undergoes structural modifications throughout the gasification reaction due to phenomena such as pore enlargement, coalescence or blocking. This leads to variations in the number of carbon active sites $C_{t}(X)$ available for the gasifying agents. The reactivity, which is a function of temperature, gas partial pressure and available reactive surface, is therefore continuously changing during the gasification. It is consequently expressed by means of a chemical kinetic term accounting for temperature and partial pressure effects $\left.R(X) T, P_{i}\right)$, and a reactivity profile $F(X)$ that aims to describe the effects of available reactive surface.

The reactivity must therefore refer to a specific conversion level. Reactivities at $10 \%$ or $50 \%$ of char conversion are often used for the determination of the kinetic parameters; the latter is actually the most commonly selected parameter in several similar investiga tions $[26,27,7]$. In our study, reactivity at $50 \%$ conversion level is taken as a reference. Assuming that the structural function does not depend on the temperature and pressure ranges of the gasifica tion experiments, the reactivity can be expressed as follows:

$R_{\left(T, P_{i}, X\right)} \quad R(50)_{\left(T, P_{i}\right)} \times F(X)$

An $n$th order kinetic model following the Arrhenius law for the reactivity temperature dependence and a power law for the reactivity gas partial pressure dependence is considered for

Table 2

Operating conditions of the gasification experiments.

\begin{tabular}{lll}
\hline Reacting medium & Reacting gas partial pressure (atm) & Temperature $\left({ }^{\circ} \mathrm{C}\right)$ \\
\hline $\mathrm{H}_{2} \mathrm{O}$ & $0.1,0.2,0.3$ & $800,850,900,950$ \\
$\mathrm{CO}_{2}$ & $0.1,0.2,0.3$ & $850,900,950$ \\
$\mathrm{H}_{2} \mathrm{O} / \mathrm{CO}_{2}$ & $0.1 / 0.1 ; 0.1 / 0.2 ; 0.2 / 0.1$ & 900
\end{tabular}

the determination of the kinetic parameters of the steam and car bon dioxide gasification reactions. The reactivity at 50\% conversion level is given by:

$$
\begin{aligned}
& R(50)_{\left(T, P_{i}\right)} \quad k_{(T)} \times P_{i}^{n} \\
& k_{(T)} \quad A \exp \left(\frac{E}{R T}\right)
\end{aligned}
$$

The reactivity profile expression can be developed from general structural models such as uniform conversion models, shrinking core models, grain models or random pore models that may con tain one or more parameters to adjust so as to match the parame ters of the experimental data [6]. It is however worth noting that the structural modifications are not solely responsible for the reac tivity change throughout the gasification. Other factors intervene, such as the char inner mineral species concentration and types [28 30,25,31], the thermal annealing phenomena occurring in par allel with the gasification reaction [32], and also the type of gasify ing media, as it has been demonstrated that the char contact with the steam drastically changes its structure into a more ordered one [33 35]. Owing to these observations and to the difficulties in determining the individual contribution of each of these parame ters on the gasification reactivity, we opted for a determination of an empirical formulation for the structural term $F(X)$ which is assumed to encompass all the influencing parameters that cause the reactivity change along the gasification reaction.

The structural function $F(X)$, which is a normalized reactivity, can be calculated at any conversion level as follows:

$$
F(X) \frac{R(X)}{R(50)}
$$

In the literature, the ratio $\frac{R(X)}{R(\text { ref })}$ is calculated within a conversion level range where experimental errors are, in the author's appreci ation, acceptable. For instance, some authors referred to a $(0.20 .8)$ conversion range with a reference at $X 0.2$ [36], others chose ranges between $(0.20 .8)$ and $(0.150 .9)$ with a reference reactivity at $X \quad 0.5[26,23]$. In our study, $F(X)$ is determined in the conver sion level range of 0.20 .9 . This range was selected to minimize weight measurement uncertainties at the small mass loss in the early stages of the reaction ( $\left.\begin{array}{lll}X & 0 & 0.2\end{array}\right)$, and to avoid high reactivity values as the mass goes to zero in the final stages of the gasification reaction $\left(\begin{array}{lll}X & 0.9 & 1\end{array}\right)$. A 5 th order polynomial regression is applied to the experimental $X$ and $F(X)$ data to determine the reactivity profile.

\section{Results and discussion}

In this section we shall first present results of HHR char gasifi cation in single atmospheres containing $\mathrm{H}_{2} \mathrm{O}$ or $\mathrm{CO}_{2}$ and then determine the intrinsic kinetic parameters and the reactivity pro files for each case. The high reactivity of the HHR chars will be also highlighted through a comparison with LHR chars. Finally we shall take a comprehensive, experiment based approach to the under standing of the mechanisms involved in char gasification in mixed atmospheres of steam and carbon dioxide. 
3.1. HHR char gasification in single atmospheres of steam and carbon dioxide

To determine the kinetic parameters and the reactivity profiles for the $\mathrm{H}_{2} \mathrm{O}$ and $\mathrm{CO}_{2}$ char gasification reactions, we performed experiments in which we varied the gas partial pressure at con stant temperatures and vice versa. Although all the possible com binations of temperature and gas partial pressure were tested, in the following sections we present only some results of reference experiments.

\subsubsection{Char $\mathrm{H}_{2} \mathrm{O}$ gasification experiments}

3.1.1.1. Influence of the temperature and $\mathrm{H}_{2} \mathrm{O}$ partial pressure on the char $\mathrm{H}_{2} \mathrm{O}$ gasification reaction. Fig. 2a and b illustrate respectively the effect of the temperature and steam partial pressure on the $\mathrm{H}_{2} \mathrm{O}$ char gasification rate.

The influence of temperature was evaluated in the range of $800950^{\circ} \mathrm{C}$. Fig. 2a shows the char conversion versus time in gas ification experiments with $20 \% \mathrm{H} 20$ in the gasifying medium at $800,850,900$, and $950^{\circ} \mathrm{C}$. Increasing the temperature from 800 to $950{ }^{\circ} \mathrm{C}$ reduced the time required for $90 \%$ conversion by a ratio of more than fivefold.

A temperature of $900^{\circ} \mathrm{C}$ was taken as a reference to evaluate the role of $\mathrm{H}_{2} \mathrm{O}$ partial pressure in the char $\mathrm{H}_{2} \mathrm{O}$ gasification reac tion. A conversion level of $90 \%$ was reached respectively after 220 , 330 , and 580 s with $\mathrm{H}_{2} \mathrm{O}$ concentrations of $30 \%, 20 \%$, and $10 \%$ in the gasifying medium. That is to say, increasing the $\mathrm{H}_{2} \mathrm{O}$ concentration from $10 \%$ to $30 \%$ results in 2.5 times higher char reactivity.

3.1.1.2. Determination of kinetic parameters for the $\mathrm{H}_{2} \mathrm{O}$ char gasi fication reaction. Adopting an $n$th order model and a reference reactivity at $50 \%$ of conversion provides a set of linear equations when taking the logarithm of both sides of Eq. (4) for the differ ent temperatures and $\mathrm{H}_{2} \mathrm{O}$ partial pressures.
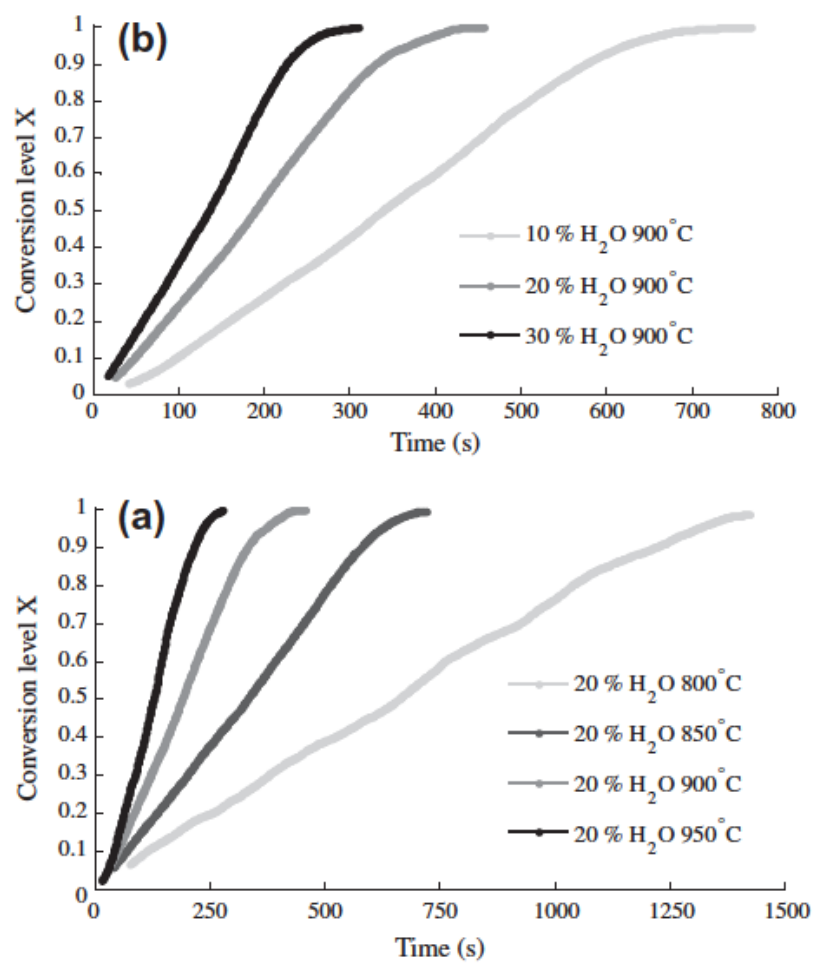

Fig. 2. Influence of the temperature (a) and steam partial pressure (b) on the char gasification rate.
$\operatorname{Ln}\left(R_{50}\right) \quad \ln (A) \quad \frac{E}{R} \frac{1}{T}+\operatorname{nln}\left(P_{\mathrm{H}_{2} \mathrm{O}}\right)$

The set of equations was put in a matrix form to determine $A, E$ and $n$ with a minimization of the error according to the least squares method. The logarithm of $R_{50}$ is plotted versus the inverse of the temperature in Fig. 3 to illustrate the temperature depen dence of the reactivity following an Arrhenius law for the different steam partial pressures.

The linear dependence of the logarithm of $R_{50}$ on the inverse of the temperature was verified with a good correlation. Similarly, the dependence of the logarithm of $R_{50}$ on the steam partial pressure for the different gasification temperatures was also verified. The correlation coefficient is superior to 0.99 , thus validating the pro posed model. The derived kinetic parameters are respectively: E $\quad 139 \mathrm{~kJ} / \mathrm{mol}, A \quad 26.30 \times 10^{3} \mathrm{~s}^{1}$ bar $^{n}$ and $n \quad 0.64$. A compari son of the char reactivity with literature data is shown in Fig. 4 for a steam partial pressure of $0.2 \mathrm{~atm}$. The conversion level at which the reactivity is calculated is indicated on the figure with the references.

The derived kinetic parameters are in accordance with recent studies on steam beech char gasification. Moreover, the activation energy and the reaction order are in the range of the values re ported in Di Blasi's review for biomass char steam gasification reactions, i.e. $40240 \mathrm{~kJ} \mathrm{~mol}^{1}$ for ' $E$ ' and 0.41 for ' $n$ ' [4].

3.1.1.3. Determination of the reactivity profile $F(X) \mathrm{H}_{2} \mathrm{O}$. Reactivity profiles for the different $\mathrm{H}_{2} \mathrm{O}$ char gasification experiments are plotted in Fig. 5. Except for a few irregularities, probably due to the measurement uncertainties, all reactivity profiles are mono tonically increasing functions and almost superposed.

The temperature and $\mathrm{H}_{2} \mathrm{O}$ partial pressure would not therefore seem to affect the reactivity evolution tendency in the studied range of parameters. The average of the functions obtained for the different gasification experiments can be expressed through:

$$
\begin{array}{ll}
F_{(X)}^{\mathrm{H}_{2} \mathrm{O}} & 0.008230 X^{5}+0.02038 X^{4}+0.11367 X^{3}+0.23074 X^{2} \\
& +0.56013 X+1.12488
\end{array}
$$

The weak influence of the temperature and $\mathrm{H}_{2} \mathrm{O}$ partial pressure on the shape of the reactivity profile was also observed by [23] whereas in Barrio's study there was a clear influence of the temper ature on the reactivity profile, especially in the final stages of con version, as the function decreased with an increase in the temperature. This can be imputable to mineral species loss or accentuated thermal annealing of the char which exhibited a lower reactivity [37].

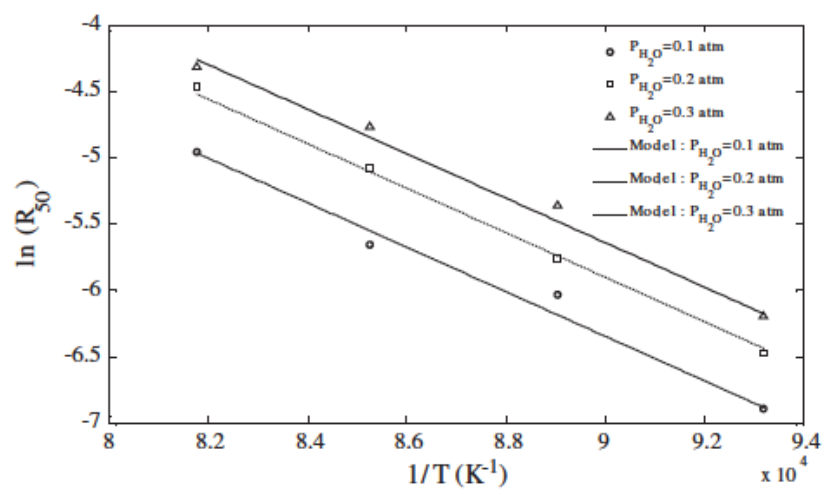

Fig. 3. Arrhenius plots for $\mathrm{H}_{2} \mathrm{O}$ gasification of HHR-chars. 


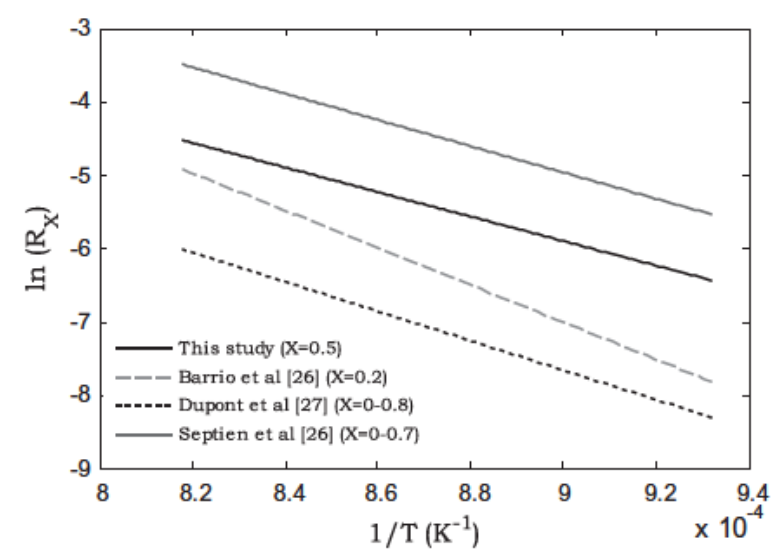

Fig. 4. Literature review on the reaction kinetics of the gasification of beech chars with steam $\left(P_{\mathrm{H} 2 \mathrm{O}}=0.2 \mathrm{~atm}\right)$.

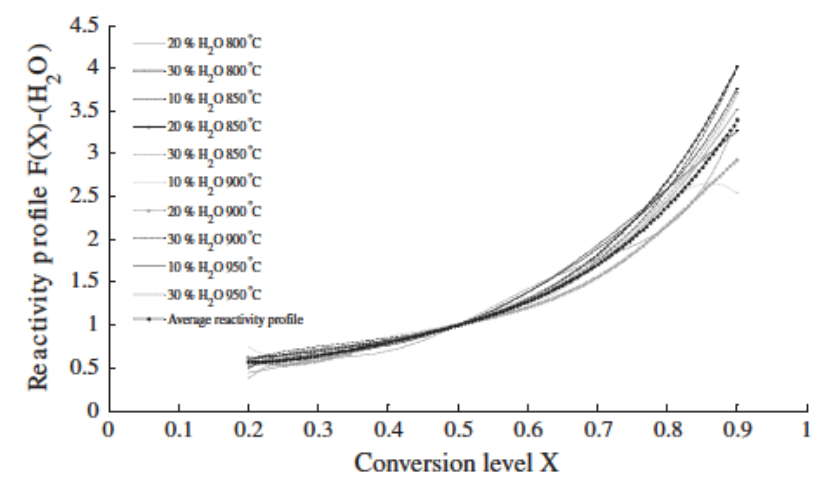

Fig. 5. Reactivity profile $F(X)$ in the $\mathrm{H}_{2} \mathrm{O}$-char gasification experiments.

\subsubsection{Char $\mathrm{CO}_{2}$ gasification experiments}

3.1.2.1. Influence of the temperature and $\mathrm{CO}_{2}$ partial pressure on the char $\mathrm{CO}_{2}$ gasification reaction. Fig. $6 \mathrm{a}$ and $\mathrm{b}$ illustrate respectively the effect of the temperature and $\mathrm{CO}_{2}$ partial pressure on the $\mathrm{CO}_{2}$ char gasification rate. Experiments with $\mathrm{CO} 2$ partial pressure of $0.2 \mathrm{~atm}$ were taken as references to evaluate the role of the tem perature. As shown in Fig. 6a, increasing the temperature by $100^{\circ} \mathrm{C}$ reduced the time required for a $90 \%$ conversion by more than 3.5 times.

The results of the char gasification experiments at a reference temperature of $900^{\circ} \mathrm{C}$ with $\mathrm{CO}_{2}$ partial pressure ranging from 0.1 to $0.3 \mathrm{~atm}$ illustrate the effect of the $\mathrm{CO}_{2}$ partial pressure on the gasification rate. Increasing the $\mathrm{CO}_{2}$ concentration in the gasifying medium from $10 \%$ to $30 \%$ allows $50 \%$ of char conversion to be reached in almost half the time. $90 \%$ conversion times are respec tively 800,590 , and 460 s in gasifying atmospheres containing $10 \%$, $20 \%$, and $30 \%$ of $\mathrm{CO}_{2}$. Similar trends were found at $850^{\circ} \mathrm{C}$ and $950^{\circ} \mathrm{C}$.

3.1.2.2. Determination of kinetic parameters for the $\mathrm{CO}_{2}$ char gasifi cation reaction. The same procedure as for steam gasification was followed to determine the kinetic parameters for the char $\mathrm{CO}_{2}$ gas ification reaction. Fig. 7 shows the Arrhenius dependence of the char reactivity on the temperature for the different $\mathrm{CO}_{2}$ partial pressures. The linear dependence between the logarithm of $R_{50}$ and the reciprocal temperature is verified with a good correlation. The solid lines in the Arrhenius represent the calculated reactivity in the temperature range of the study.
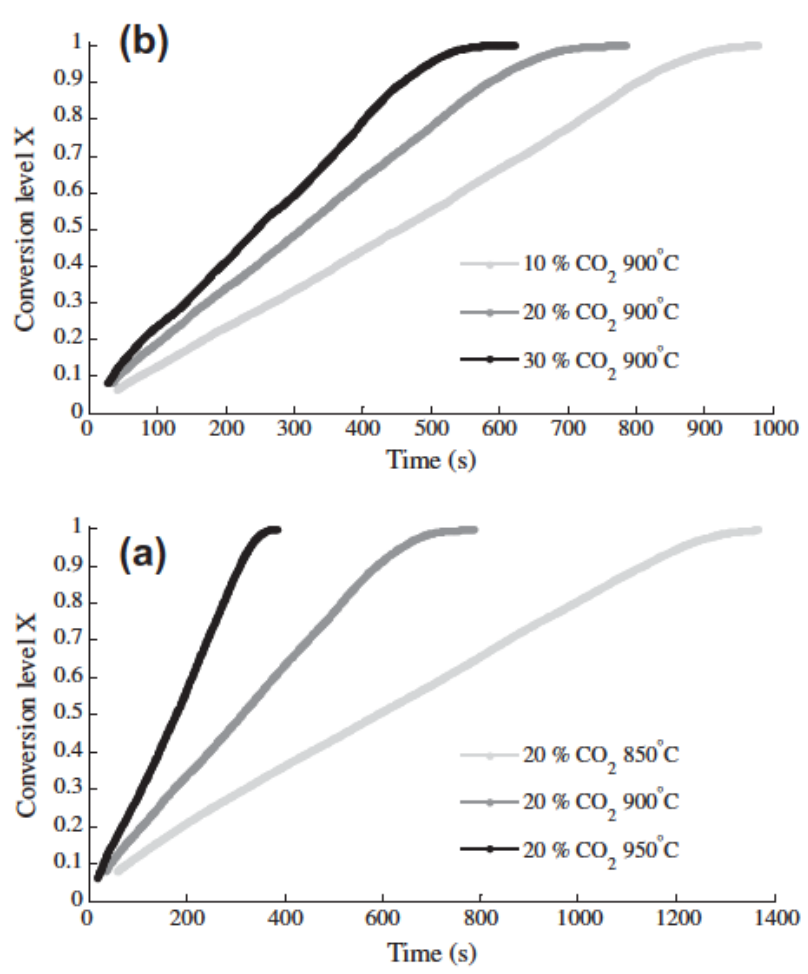

Fig. 6. Influence of the temperature (a) and $\mathrm{CO}_{2}$ partial pressure (b) on the char gasification rate.

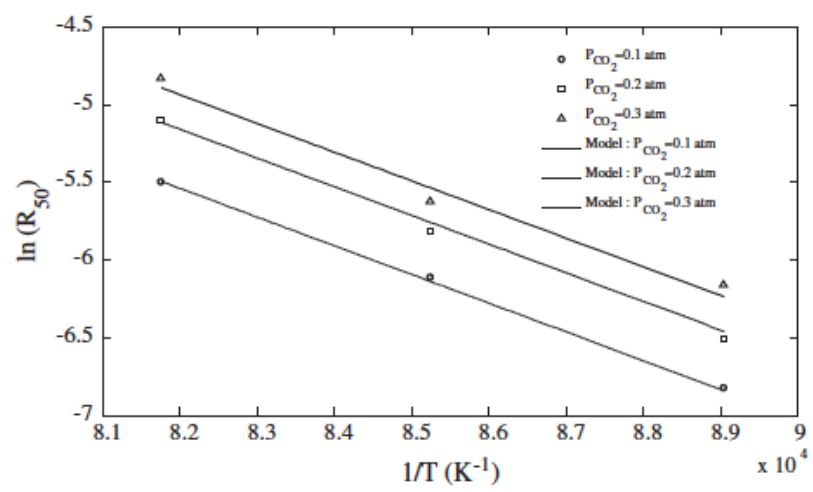

Fig. 7. Arrhenius plots for $\mathrm{CO}_{2}$ gasification of HHR-chars.

Likewise, we obtained a linear dependence of the logarithms of $\mathrm{R}_{50}$ and $\mathrm{CO}_{2}$ partial pressure at the different gasification tempera tures. The results are not plotted here.

The model is also verified for $\mathrm{CO}_{2}$ gasification experiments with a very good determination coefficient $R^{2} \quad 0.996$. The derived ki netic parameters are: E $154 \mathrm{~kJ} / \mathrm{mol}, A 55.18 \times 10^{3} \mathrm{~s}^{1}$ bar $^{n}$ and $n \quad 0.55$, which are in the respective value ranges reported in Di Blasi's review for biomass char $\mathrm{CO}_{2}$ gasification reactions [4].

3.1.2.3. Determination of the reactivity profile $\mathrm{F}(\mathrm{X}) \mathrm{CO}_{2}$. Fig. 8 shows the reactivity profiles obtained for the $\mathrm{CO}_{2}$ char gasification exper iments at different temperatures and $\mathrm{CO}_{2}$ partial pressure. The char reactivity increases with the gasification; this reactivity tendency is typical of the majority of biomass chars in contrast with that of coal chars, which decreases as the conversion level increases [38]. 


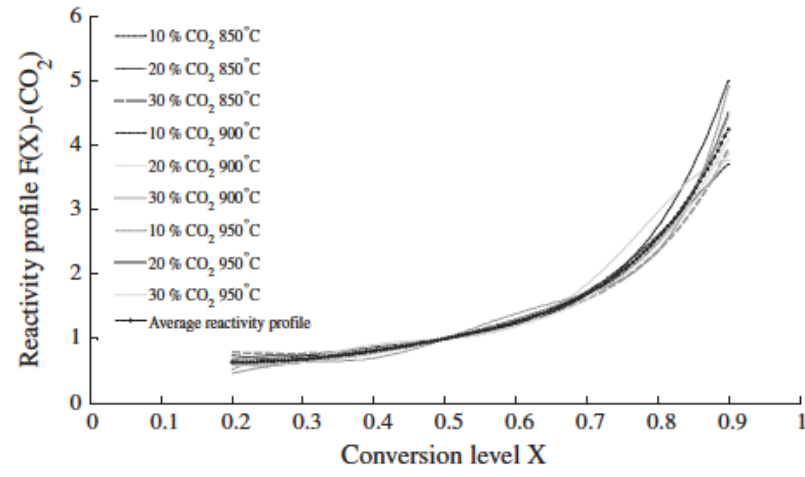

Fig. 8. Reactivity profile $F(X)$ in the $\mathrm{CO}_{2}$-char gasification experiments.

Apart from small discrepancies, all the reactivity profiles are superposed. Neither the temperature nor the $\mathrm{CO}_{2}$ concentration af fects the reactivity profile. The reactivity profile is clearly related to other phenomena such as the structural modifications and the increasing concentration of minerals in the biomass char, as sug gested in many similar studies. Weak effects of the temperature and $\mathrm{CO}_{2}$ partial pressure on the reactivity profile were observed in the work of Vandesteene et al. [23], while the temperature clearly affected the reactivity profile for birch char gasification experiments, as presented elsewhere [36].

The average of the obtained functions in the different gasifica tion experiments has the following expression:

$$
\begin{array}{ll}
F_{(X)}^{\mathrm{CO} 2} & 0.014422 X^{5}+0.081024 X^{4}+0.1379 X^{3}+0.2142 X^{2} \\
& +0.5254 X+1.1175
\end{array}
$$

\subsubsection{HHR chars high reactivity}

In order to highlight the higher reactivity of the HHR chars, we performed gasification experiments under respectively $20 \%$ of steam and $20 \%$ of $\mathrm{CO}_{2}$ at $900{ }^{\circ} \mathrm{C}$ with the beech char particles pre pared with a low heating rate $\left(5^{\circ} \mathrm{C} / \mathrm{min}\right)$. The results are plotted in Fig. 9 in terms of average reactivity calculated in the conversion range of $2090 \%$. The effect of the heating rate is clear, as the HHR char reactivity was more than 3.5 times higher in $20 \%$ of steam than for the LHR char in the same operating conditions. Sim ilarly, the LHR char reactivity in an atmosphere containing $20 \%$ $\mathrm{CO}_{2}$ was estimated at $0.001 \mathrm{~g} /(\mathrm{g} \mathrm{s})$ while it was 4.3 times higher for the HHR char in the same operating conditions.

These results are in accordance with the literature [25,19,39], although the effect of the heating rate on the char reactivity is much more pronounced in the present study than in that of
Guerrero et al. [19] for eucalyptus char gasification, and comes close to the observations made by Mermoud et al. [25].

In the work of Guerrero et al. [19], the increase in the char reac tivity with the HR was not as marked as in the present work or in that of Mermoud et al. [25]. Mermoud et al. found that the char yields under low and high heating rates were respectively $24.3 \%$ and $14.2 \%$ with an increase in the ash amount when increasing the heating rate. The effect of the heating rate on the char reactiv ity with steam was as significant as it is in the present work, since the HHR char reactivity was 2.6 times higher than that of the LHR char. The authors concluded that besides the more porous struc ture obtained in HHR chars, the mineral species seems to play a crucial role.

In the present work, the HHR chars exhibited high gasification rates which may be imputable to two main factors: the small par ticle thickness and the high pyrolysis heating rate. The former fac tor minimizes the mass transfer limitations while the second leads to a highly porous char having a mineral content more than twice as high as that of LHR char. These combined parameters are known to greatly enhance the char reactivity.

\subsection{Char gasification in mixture of $\mathrm{H}_{2} \mathrm{O}+\mathrm{CO}_{2}$}

In order to study the effect of introducing the $\mathrm{CO}_{2}$ as a co reac tant alongside steam, we performed gasification experiments at $900^{\circ} \mathrm{C}$ with a steam concentration of $10 \%$ and a $\mathrm{CO}_{2}$ concentration increasing from $0 \%$ to $30 \%$. Conversion levels versus time plots are shown in Fig. 10.

The $\mathrm{CO}_{2}$ introduction clearly enhances the reaction rate. $90 \%$ conversion time was about 580 s with $10 \% \mathrm{H}_{2} \mathrm{O}$ and no $\mathrm{CO}_{2}$ in the gasifying medium but decreased with the increase in the $\mathrm{CO}_{2}$ concentration in the input gas to $215 \mathrm{~s}$ with a $\mathrm{CO}_{2}$ molar fraction of $30 \%$. The evolution of the char average reactivity calculated in the conversion range of $2090 \%$ with the increasing $\mathrm{CO}_{2}$ con centration is illustrated in Fig. 11. The average reaction rate with $20 \%$ of $\mathrm{CO}_{2}$ introduced alongside steam was twice that of free $\mathrm{CO}_{2}$ gasification experiments with only $10 \%$ steam in the gasifying medium.

It is clear that the introduction of the $\mathrm{CO}_{2}$ would not inhibit the gasification reaction, as proposed elsewhere [7]. This assumption is not valid for the present gasification experiments.

To gain greater understanding of the gasification reaction in the $\mathrm{CO}_{2} / \mathrm{H}_{2} \mathrm{O}$ mixture, we compared the char reactivity obtained in mixed atmospheres with the sum of the reactivities obtained in single atmosphere experiments for the same steam and carbon dioxide partial pressures.

Reactivity curves in the conversion range of $2090 \%$ are plotted in Fig. 12. Apart from small discrepancies probably due to experi

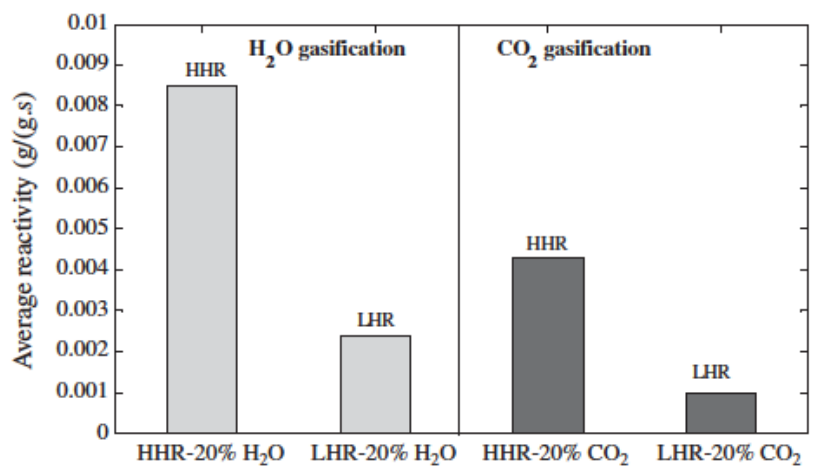

Fig. 9. HHR and LHR char average reactivity at $900^{\circ} \mathrm{C}$.

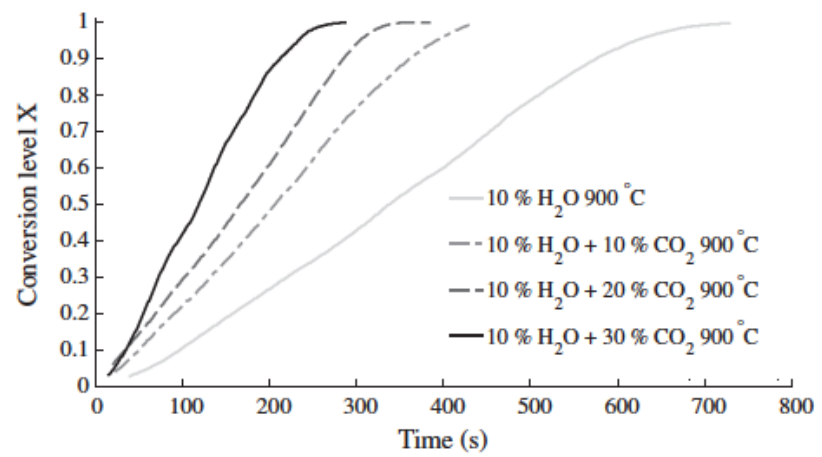

Fig. 10. Effect of the $\mathrm{CO}_{2}$ co-feeding next to steam on the gasification reaction rate. 


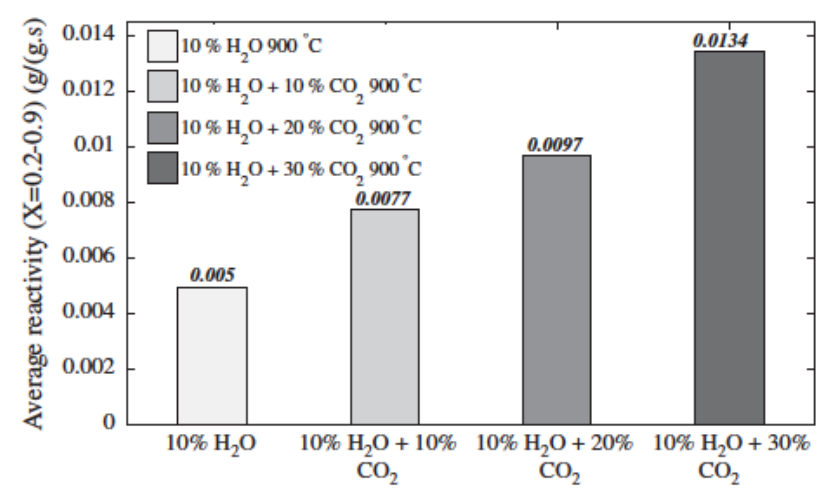

Fig. 11. Char average reactivity evolution with the increasing amount of $\mathrm{CO}_{2}$ introduced next to $10 \%$ steam.

mental errors, an additive law is valid to describe char gasification under mixed atmospheres.

A first $a$ priori conclusion would be that $\mathrm{H}_{2} \mathrm{O}$ and $\mathrm{CO}_{2}$ are oper ating on separate active sites (Passive cooperation). Nevertheless, this observation may be due to two opposed actions resulting in an "apparent additive law". To further interpret this result, we pro pose in the next section a detailed reflexion based on a literature review and on additional gasification experiments.

3.2.1. On the understanding of the char gasification reaction in mixed atmospheres of $\mathrm{CO}_{2}+\mathrm{H}_{2} \mathrm{O}$

3.2.1.1. Literature review and discussion. Concerning the mecha nisms involved in the char gasification reaction in mixed atmo spheres, three main assumptions are held in the literature:
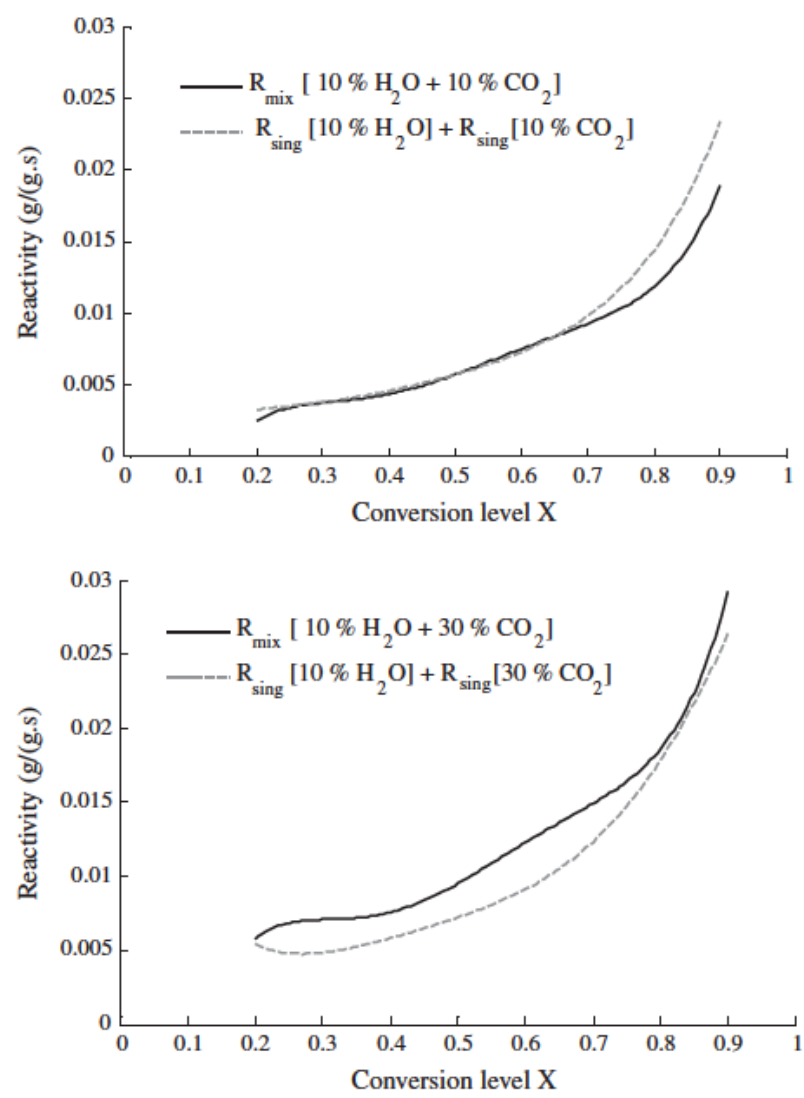

$\mathrm{CO}_{2}$ and $\mathrm{H}_{2} \mathrm{O}$ gasification reactions occurring on common active sites (Inhibition): In a previous study on coal char gasification, the authors observed that the char reactivity decreased when add ing $\mathrm{CO}_{2}$ alongside steam and concluded that there was a competi tion between the two gases for the access to the carbon active sites [7]. Although the chars are different (coal and biomass chars) which may lead to different results, the authors limit their obser vations to the first $10 \%$ of char conversion, which is not represen tative of the overall gasification reaction. The coal char may exhibit a different behavior beyond $10 \%$ of conversion, mainly when pores open more widely and gasification spreads homoge neously through the particle. In a more recent study, the authors found the char $\mathrm{H}_{2} \mathrm{O}$ gasification reaction was independent of the char $\mathrm{CO}_{2}$ reaction, while the latter is inhibited by the former [9]. Others proposed a model based on a partial sharing of active sites. The two gases are competing in part of the active sites, while react ing separately in their own ones [8].

This assumption is clearly not valid regarding the result of the present study. Other studies on coal char gasification showed that there was no inhibition between the gasifying agents, but rather a passive cooperation on separate active sites $[11,10,34]$. This will be discussed in the next paragraph.

$\mathrm{CO}_{2}$ and $\mathrm{H}_{2} \mathrm{O}$ gasification reactions on separate active sites (Passive cooperation): The model of passive cooperation assumes that the two gases react on separate active sites without influencing each other. In their study on coal char gasification, Bliek et al. [12] found that the overall carbon conversion rate in the presence of $\mathrm{CO}_{2}$ and $\mathrm{H}_{2} \mathrm{O}$ is the sum of the single char reactivities. This assumption was also held by Tay et al. [34] for coal char gasification. The authors found that the gasification rate in mixed atmospheres of $\mathrm{O}_{2}+\mathrm{H}_{2} \mathrm{O}+\mathrm{CO}_{2}$ was approximately equal to the sum of the gasification rates in the respective single atmospheres. They suggest that the additivity in
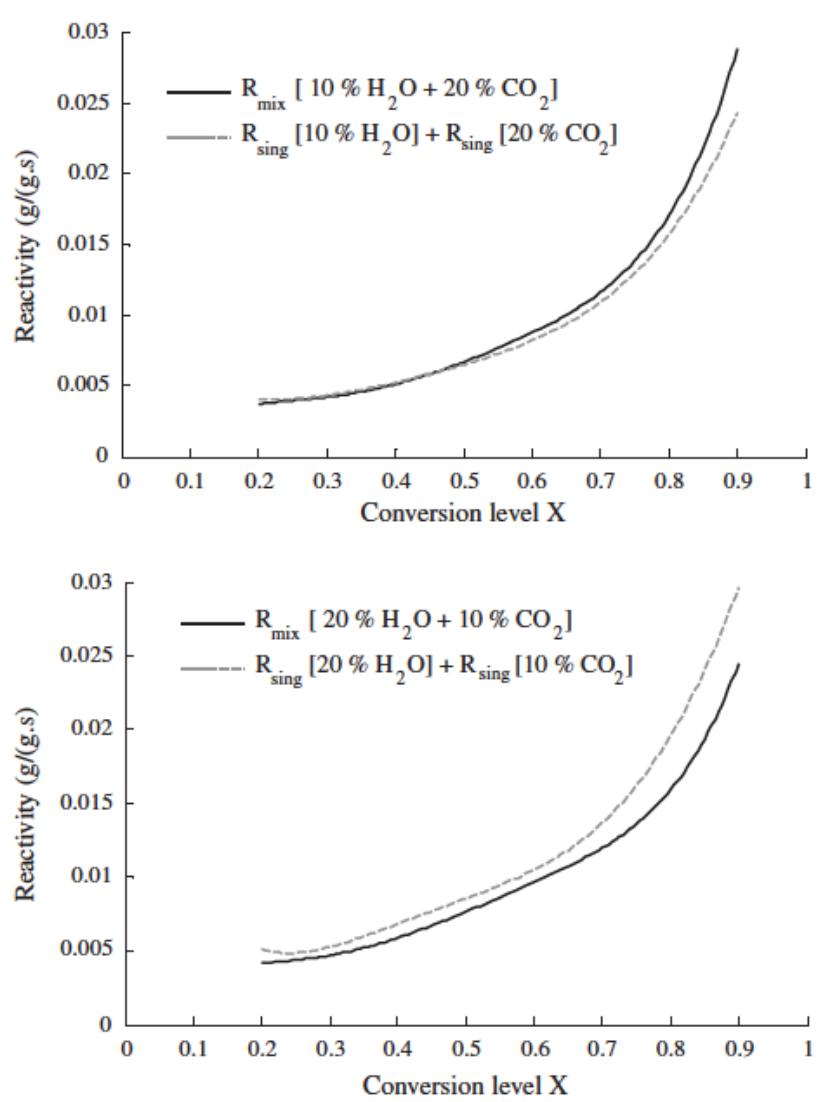

Fig. 12. Comparison of the HHR-char reactivity in mixed atmosphere with the sum of the single reactivities for different gasifying medium composition at $900{ }^{\circ} \mathrm{C}$ 
char conversion rates means that $\mathrm{O}_{2}, \mathrm{H}_{2} \mathrm{O}$ and $\mathrm{CO}_{2}$ do not compete for the same active sites on the coal char but are rather operating on separate active sites. Similar conclusions can be found elsewhere for the coal char gasification reaction in mixed atmospheres con taining $\mathrm{CO}_{2}$ and $\mathrm{H}_{2} \mathrm{O}[11,10]$. In both of these studies, 2 models based on the assumptions of char $\mathrm{CO}_{2}$ and char $\mathrm{H}_{2} \mathrm{O}$ reactions occurring on common and separate active sites were tested. The model assum ing reactions on separate active sites fitted the experimental results well, whereas the model assuming competition for the same carbon active sites under predicted the experimental results.

Minkova et al. [40] also performed gasification experiments of birch wood, straw and miscanthus pellets in non isothermal condi tions ( $\mathrm{HR} 10^{\circ} \mathrm{C} / \mathrm{min}$ ) up to a temperature of $750^{\circ} \mathrm{C}$ with a resi dence time of $2 \mathrm{~h}$, and found that the yield of solid product is lower in a mixed atmosphere of $\mathrm{CO}_{2}+\mathrm{H}_{2} \mathrm{O}$ than with steam only, which means that the $\mathrm{CO}_{2}$ is also participating in the global gasifi cation reaction. They also observed that the $\mathrm{CO}_{2}+\mathrm{H}_{2} \mathrm{O}$ gasification environment leads to a more developed pore structure and surface area, which is merely the result of an advanced stage of the bio mass gasification reaction.

In a more recent study on sewage sludge gasification in a fluid ized bed, the authors found that the reaction rate in a mixture of $\mathrm{CO}_{2}+\mathrm{H}_{2} \mathrm{O}$ is well represented by the sum of the individual reaction rates obtained with $\mathrm{CO}_{2}$ and $\mathrm{H}_{2} \mathrm{O}$ individually [13].

Synergy between $\mathrm{CO}_{2}$ and $\mathrm{H}_{2} \mathrm{O}$ (Active cooperation): This model assumes that besides reaction on separate active sites, there is an active cooperation between the gases for the accessibility to the carbon active sites. At least one of the reactants is supposed to act in a certain way as to enhance the char reactivity towards the second gas. Such an action can be, for example, the creation of additional porosity, as proposed by Butterman and Castaldi [15], or the retention of catalytic mineral species inside the char, as mentioned elsewhere [34].
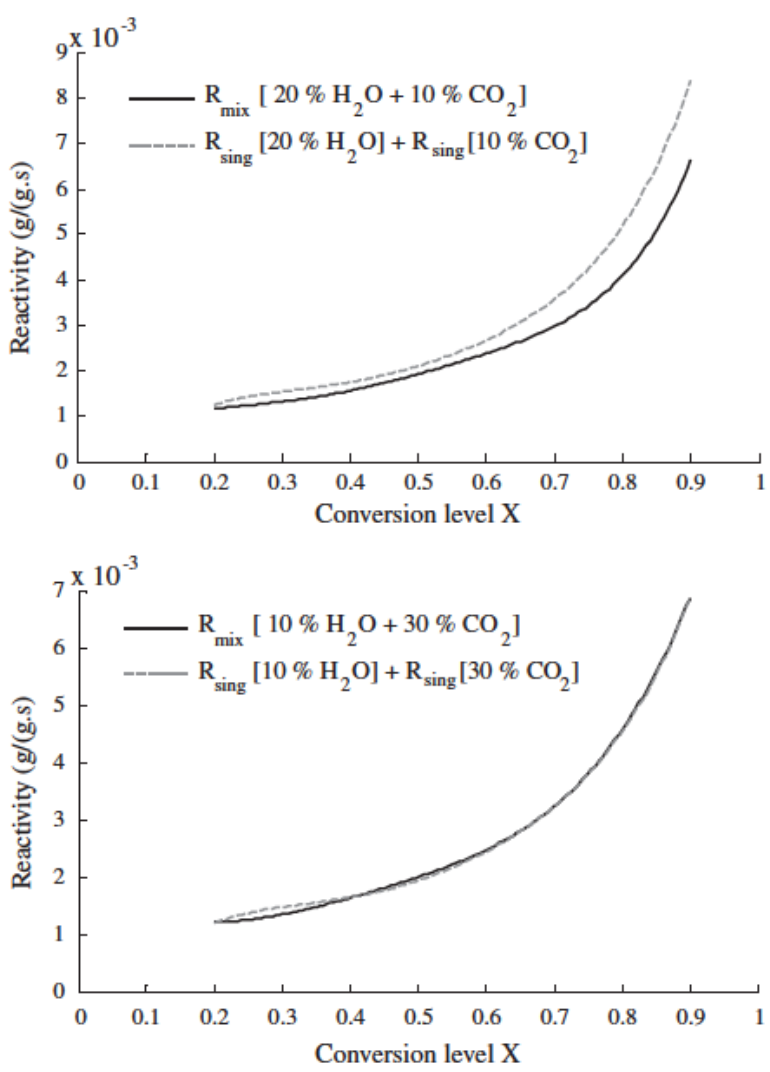

Recently, in their study on pine char gasification, Tagutchou et al. [14] proposed a model where the $\mathrm{CO}_{2}$ and $\mathrm{H}_{2} \mathrm{O}$ cooperate to gether for accessibility to the carbon active sites. The authors found that the char reactivity in a mixed atmosphere was higher than the sum of the reactivities obtained in single atmospheres of $\mathrm{CO}_{2}$ and $\mathrm{H}_{2} \mathrm{O}$. They concluded that a cooperative effect of the two reactants with char gasification reactions occurred on separate active sites, but they did not go further into the understanding of the mecha nisms involved.

Butterman and Castaldi [15] also think that $\mathrm{CO}_{2}$ alongside steam may lead to an enhanced reactivity, as it could further devel op the porosity inside the char particle and provide a greater reac tive surface. The authors performed gasification experiments on several biomasses in a TG apparatus with a heating rate of $10^{\circ} \mathrm{C} /$ min and observed that the total number of pores during $\mathrm{CO}_{2}$ ther mal treatment was an order of magnitude greater than that ob served during $\mathrm{H}_{2} \mathrm{O} / \mathrm{N}_{2}$ processing. Even the range in pore sizes was much more extended with $\mathrm{CO}_{2}(250 \mu \mathrm{m})$ than with steam (10 $20 \mu \mathrm{m}$ ). They also observed that the gasification was com pleted when introducing $30 \%$ of $\mathrm{CO}_{2}$ with the steam, while a black char residue remained when using only steam as a gasification medium.

As regards the results obtained in the present study, the most plausible assumption would be that the two reactants are operat ing in separate active sites without any kind of synergy. Still, we cannot draw a definitive conclusion without taking into consider ation the observations of Tagutchou et al. [14] and Butterman and Castaldi [15]. For this reason, we performed two other types of char gasification experiments: (i) with LHR chars, so as to come closer to Tagutchou's experimental conditions in terms of HR, (ii) char gasification experiments with gas transition, wherein the char is firstly operated with $\mathrm{CO}_{2}$ up to a defined conversion level and then gasified with steam to see if the $\mathrm{CO}_{2}$ influences the char
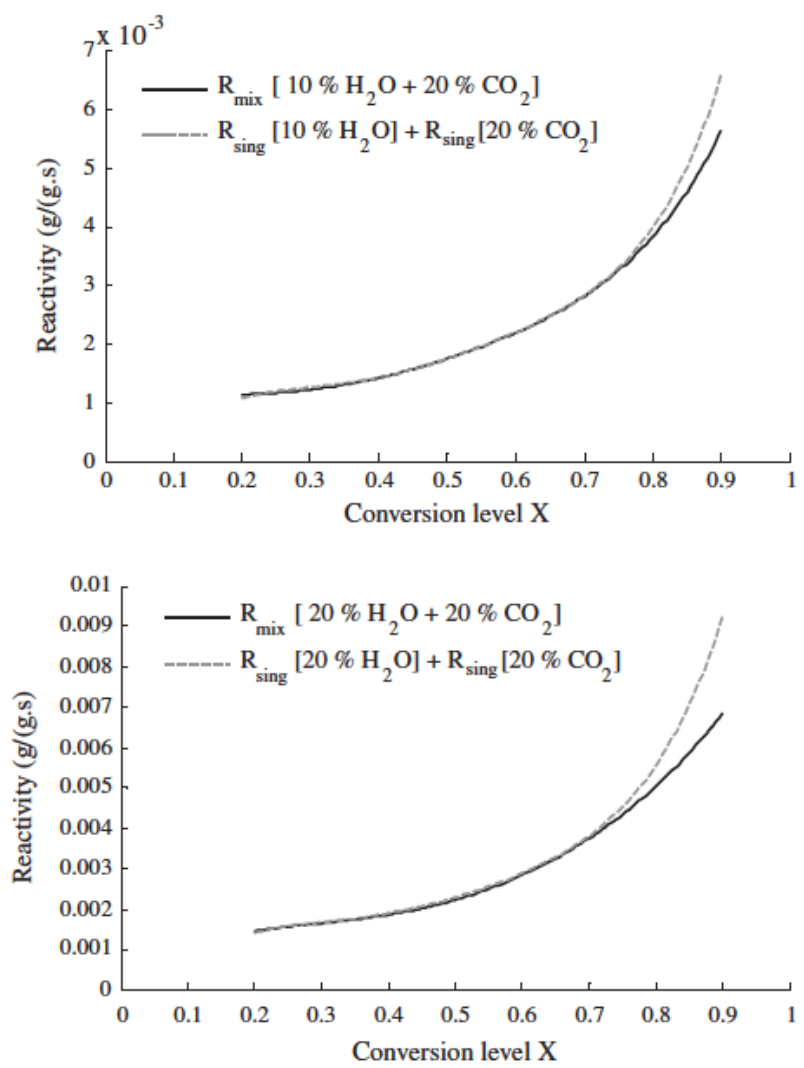

Fig. 13. Comparison of the LHR-char reactivity in mixed atmosphere with the sum of the single reactivities for different gasifying medium composition at $900{ }^{\circ} \mathrm{C}$. 
physical properties and consequently impacts its reactivity toward steam.

\subsubsection{Reactivity of LHR chars in mixed atmospheres of $\mathrm{H}_{2} \mathrm{O}+\mathrm{CO}_{2}$}

Unlike in our experiments, Tagutchou et al. used char particles with a greater thickness $(5 \mathrm{~mm})$ and prepared with a relatively low heating rate $\left(60^{\circ} \mathrm{C} / \mathrm{min}\right)$ in a screw pyrolysis reactor. Unsurpris ingly, the differences in operating conditions for the char prepara tion led to chars with different reactivities and morphological features (available reactive surface and pore opening). Chars pre pared at a high heating rate already have their pores open and present a high surface area, whereas those prepared at a low heat ing rate have a less developed reactive surface and a narrower por ous network $[39,19,25]$.

We performed additional gasification experiments with LHR char in mixed atmospheres of steam and carbon dioxide to see if the additivity of single reactivities is valid for LHR chars. The re sults are plotted in Fig. 13.

The reactivity curves obtained in mixed atmospheres match very well with those of the added single reactivities, except for a small deviation observed for the gasifying atmosphere composed of $10 \% \mathrm{CO}_{2}+20 \% \mathrm{H}_{2} \mathrm{O}$. Additivity of reactivities is again a valid assumption for the LHR char. The heating rate would therefore only impact the reaction rate but not on the reaction mechanisms in a mixed atmosphere. Other authors found that the contributions of the char $\mathrm{H}_{2} \mathrm{O}$ reaction and char $\mathrm{CO}_{2}$ reaction in the global mixed atmosphere reaction rate remained the same indepen dently of the pyrolysis heating rate [9]. This is in accordance with our findings.

If we assume that there is no influence from the type of biomass (pine and beech wood), we believe that in Tagutchou's work, it is more likely that it is the char particle thickness that influences the global reaction rate and the mixed atmosphere gasification mechanisms. Because of internal diffusion limitations for the $\mathrm{CO}_{2}$
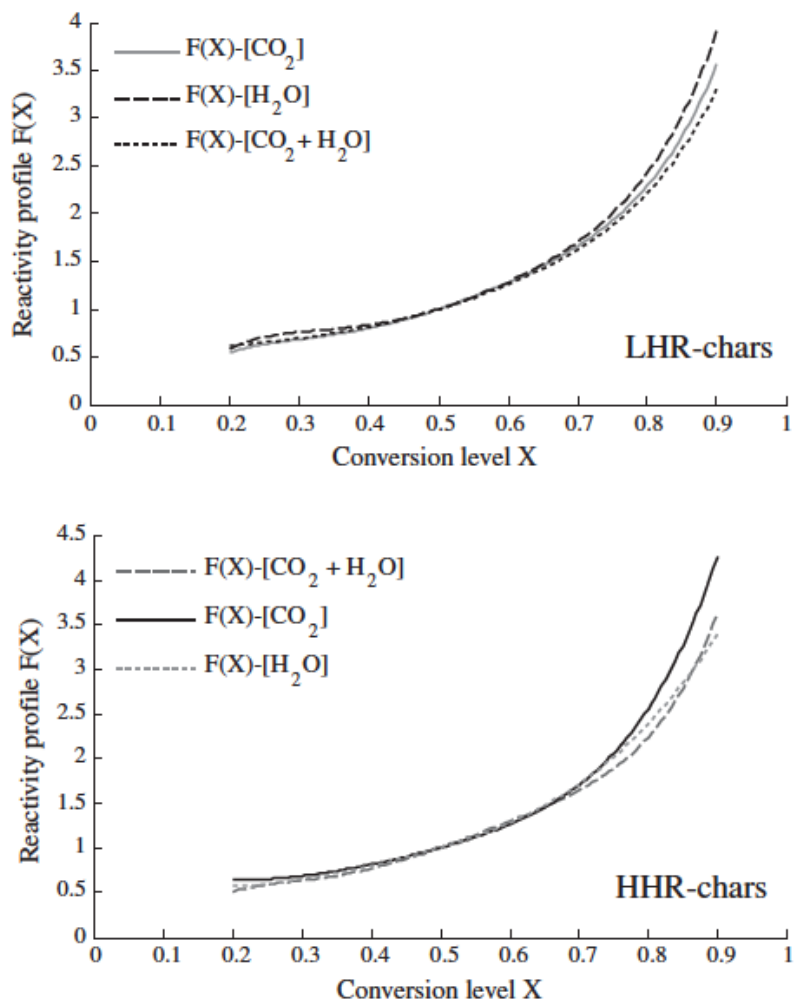

Fig. 14. Comparison of the average reactivity profiles for steam and carbon dioxide gasification experiments. molecules, due to a greater particle thickness $(5 \mathrm{~mm})$ in compari son with the present case, the enhancement of the gasification reaction observed by Tagutchou in mixed atmosphere conditions may be due to the fact that the steam gasification reaction further developed the char's internal porosity and ameliorated the access of the $\mathrm{CO}_{2}$ molecules to the heart of the char particle, which re sulted in an apparent reactivity that was greater than the sum of the respective single reactivities.

The additive law would therefore be valid as long as the char particle is thin enough to prevent internal diffusion limitations to ward the $\mathrm{CO}_{2}$ molecules. This possible explanation must be further investigated by comparing the effect of the particle thickness respectively on the $\mathrm{H}_{2} \mathrm{O}$ and $\mathrm{CO}_{2}$ gasification reaction rates.

Another fact worth noting is that the average reactivity profiles for $\mathrm{H}_{2} \mathrm{O}, \mathrm{CO}_{2}$ and mixed atmosphere gasification experiments for HHR and LHR chars are practically the same, except for some devi ations for higher conversion levels that can be attributed to mea surement uncertainties, as depicted in Fig. 14.

This tendency was not observed, for example, by Tagutchou et al. $[14,23]$ who found different reactivity profiles for $\mathrm{CO}_{2}$ and $\mathrm{H}_{2} \mathrm{O}$ gasification experiments. The authors observed that the $\mathrm{H}_{2} \mathrm{O}$ reactivity profile showed a continuous increase throughout the conversion while the $\mathrm{CO}_{2}$ reactivity profile did not go beyond the value of 1 until a conversion level of $80 \%$, from which it began to increase. In other words the char reactivity did not increase in the range of $5080 \%$ of conversion. This may be due to the limited access of the $\mathrm{CO}_{2}$ molecules to the heart of the char particle, de spite the advanced gasification stage. In the present study, the sim ilarity of the reactivity profiles may be imputed to the absence of internal diffusion limitations due to the particle's lower thickness. Once again, this assumption needs to be investigated further.

\subsubsection{Gas alternation gasification experiments}

The aim of such experiments is to verify whether or not there is a kind of synergy, as claimed by Butterman et al. $[14,15]$, that leads in the present case to an apparent additive law. The $\mathrm{CO}_{2}$ is first introduced as a gasifying reagent to establish whether or not it cre ates additional porosity and further develops the reactive surface for $\mathrm{H}_{2} \mathrm{O}$. The unfolding of this type of experiment comprises three stages:

- Char gasification with $\mathrm{CO}_{2}$ up to a certain conversion level.

- Stopping the $\mathrm{CO}_{2}$ flow, stabilization of the mass and purge of the reactor under $\mathrm{N}_{2}$.

- Introduction of steam and pursuance of the gasification reaction up to total conversion.

The first experiment was performed on a HHR char that was gasified with $20 \% \mathrm{CO}_{2}$ up to a conversion level of $28 \%$ and subse quently operated with $10 \%$ of steam. The second one, on a LHR char, was performed with $20 \%$ of $\mathrm{CO}_{2}$ up to a conversion level of $35 \%$ followed by steam gasification with a steam concentration of $20 \%$ in the gas flow. Fig. 15a and b illustrate the unfolding of these experiments. On these figures are plotted reference char reactivi ties obtained in single atmospheres of steam and carbon dioxide (gray and black solid lines) and the char reactivity in the gas alter nation experiment (black dashed line).

For the HHR and LHR chars, in the first stage of the gas alterna tion experiment, the char reactivity curve naturally follows the ref erence curve obtained under a $\mathrm{CO}_{2}$ containing atmosphere. No results are reported during the gas transition zone. We can clearly see on the two figures that the char reactivity curve in the $\mathrm{H}_{2} \mathrm{O}$ gasification stage re joins the reference curve obtained with the reference steam containing atmosphere. If the $\mathrm{CO}_{2}$ had changed the char's properties, we would have seen an enhancement or a de crease in the char's reactivity towards $\mathrm{H}_{2} \mathrm{O}$; it is not the case here. 

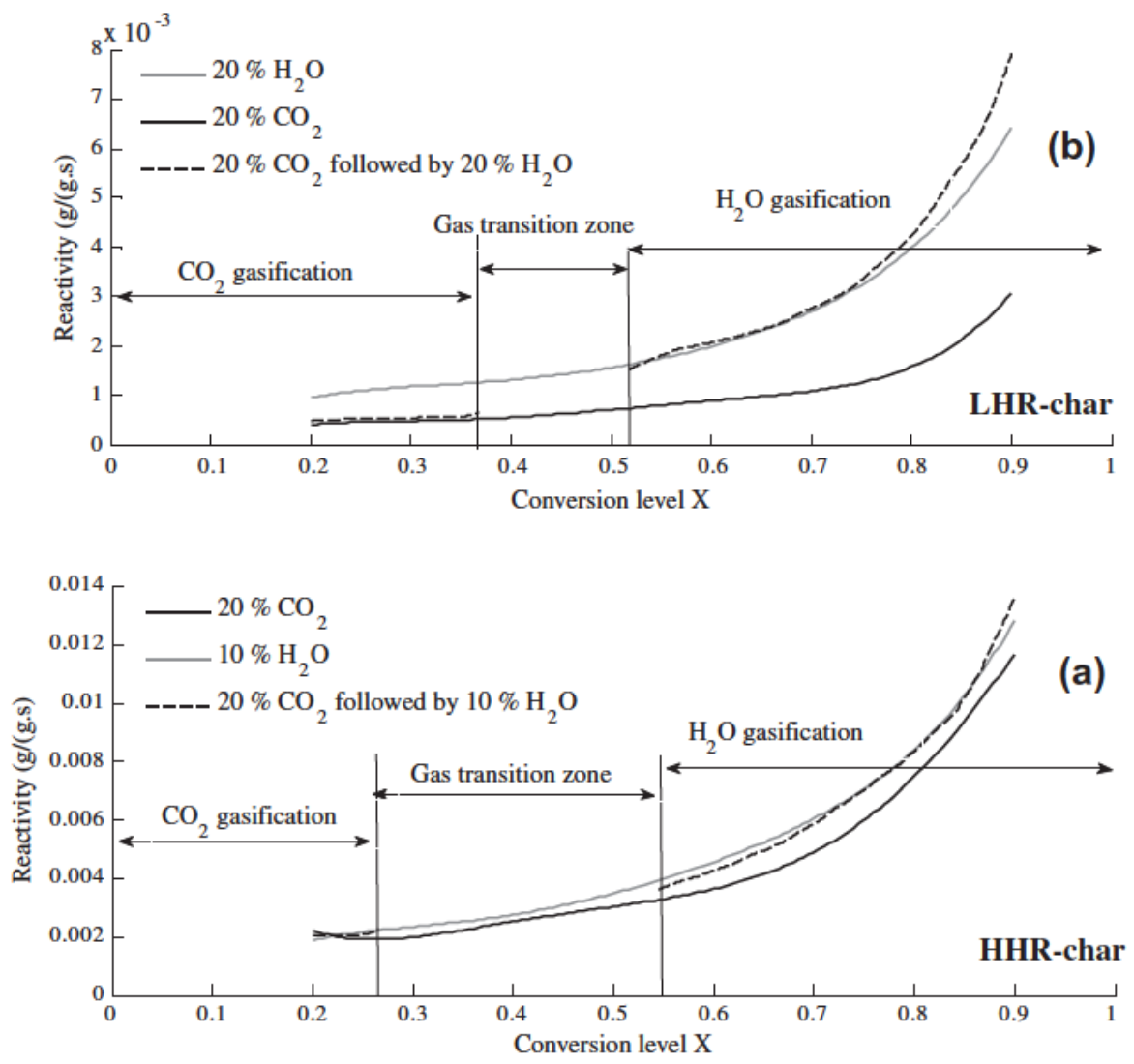

Fig. 15. HHR-char (a) and LHR-char (b) gasification experiments with alternance of $\mathrm{CO}_{2}$ and $\mathrm{H}_{2} \mathrm{O}$ at $900{ }^{\circ} \mathrm{C}$.

On the basis of these observations, the most likely explanation for the observed additive law would be that the $\mathrm{CO}_{2}$ and $\mathrm{H}_{2} \mathrm{O}$ are oper ating on separate active sites without any kind of synergy. This con clusion is to be taken with precaution, as there can be other phenomena when the two gases are reacting simultaneously. None theless it constitutes a step forward in the understanding of the mechanisms involved in char gasification in mixed atmospheres.

Finally, the observation of Butterman and Castaldi [15] concern ing the incomplete char burnout with only steam as reactant may be a consequence of an ordering of the carbon structure due to the thermal annealing that is promoted by the contact with steam, as proposed elsewhere for coal and biomass char gasification $[33,34]$. Introducing $30 \%$ of $\mathrm{CO}_{2}$ would have overcome the structural order ing of the carbon matrix as the rate of the gasification reaction would then be higher than that of the carbon ordering and result in complete char burnout.

For our study, in view of the results obtained and the literature review and discussion, the char reactivity in a mixed atmosphere of $\mathrm{CO}_{2}+\mathrm{H}_{2} \mathrm{O}$ can be written as the sum of the single reactivities:

$R_{\mathrm{H}_{2} \mathrm{O}+\mathrm{CO}_{2}} \quad R_{\mathrm{H}_{2} \mathrm{O}}+R_{\mathrm{CO}_{2}}$

\section{Conclusion}

The new macro TG experimental device allowed us to perform gasification experiments on beech chars prepared at high heating rates. These experimental conditions are of interest as they come close to those encountered in fluidized beds. The fast pyrolysis was followed directly by gasification experiments without addi tional heating of the char particle to the gasification temperature, as is usually done in conventional TG devices. Reliable kinetic data were obtained for HHR char gasification reactions with $\mathrm{H}_{2} \mathrm{O}$ and $\mathrm{CO}_{2}$ and can be used for the design and optimization of fluidized bed gasifiers.

The heating rate greatly affects the char reactivity to $\mathrm{H}_{2} \mathrm{O}$ as well as to $\mathrm{CO}_{2}$. The HHR char reactivity was 3.5 times higher in $\mathrm{H}_{2} \mathrm{O}$ gasification and greater than fourfold with $\mathrm{CO}_{2}$ in comparison with LHR chars.

Introducing $\mathrm{CO}_{2}$ alongside steam resulted in a higher reactivity of the beech char, regardless of the pyrolysis conditions (low or high heating rate). For a $\mathrm{HHR}$ char, increasing the $\mathrm{CO}_{2}$ concentra tion from $0 \%$ to $30 \%$ in a $10 \%$ steam containing atmosphere re sulted in a 2.7 times higher char reactivity.

A comprehensive approach was established in order to clarify further the mechanisms involved in mixed atmosphere gasification reactions. The present work demonstrates the validity of an addi tive law reflecting a passive cooperation of steam and carbon diox ide in the gasification reaction. Specific experiments carried out in this work showed that converting a char under $\mathrm{CO}_{2}$ to approxi mately $X \quad 30 \%$ did not affect its reactivity during further conver sion under $\mathrm{H}_{2} \mathrm{O}$.

The additive law would appear to be valid as long as the particle is thin enough to prevent diffusional limitation phenomena toward the $\mathrm{CO}_{2}$ molecules. We believe that the steam gasification reaction would facilitate the access of $\mathrm{CO}_{2}$ molecules to the heart of the char particle in the case of thick particles, resulting in an apparent en hanced reactivity.

\section{Acknowledgements}

The authors acknowledge the national research agency ANR France for its financial support in the RECO2 project. They also 
wish to express their appreciation to Bernard Auduc for his techni cal support. Finally, the authors would also like to thank Laurent Bedel and Sylvie Valin for their assistance and insightful conversations.

\section{References}

[1] A Florides G, Christodoulides P. Global warming and carbon dioxide through sciences. Environ Int 2009;35(2):390-401.

[2] Dhillon RS, Von Wuehlisch G. Mitigation of global warming through renewable biomass.pdf. Biomass Bioenergy 2013;48:75-89.

[3] Basu P. Biomass gasification and pyrolysis: practical design and theory. Elsevier; 2010 p. 365.

[4] Di Blasi C. Combustion and gasification rates of lignocellulosic chars. Progr Energy Combust Sci 2009;35(2):121-40.

[5] Kumar A, Jones DD, Hanna MA. Thermochemical biomass gasification: a review of the current status of the technology. Energies 2009;2(3):556-81.

[6] Gómez-Barea A, Leckner B. Modeling of biomass gasification in fluidized bed. Progr Energy Combust Sci 2010;36(4):444-509.

[7] Roberts DG, Harris DJ. Char gasification in mixtures of $\mathrm{CO}_{2}$ and $\mathrm{H}_{2} \mathrm{O}$ : competition and inhibition. Fuel 2007;86(17-18):2672-8.

[8] Umemoto S, Kajitani S, Hara S. Modeling of coal char gasification in coexistence of $\mathrm{CO}_{2}$ and $\mathrm{H}_{2} \mathrm{O}$ considering sharing of active sites. Fuel 2011(November).

[9] Chen $C$ et al. Effect of pyrolysis conditions on the char gasification with mixtures of $\mathrm{CO}_{2}$ and $\mathrm{H}_{2} \mathrm{O}$. Proc Combust Inst 2012(August).

[10] Huang $\mathrm{Z}$ et al. Kinetic studies of char gasification by steam and $\mathrm{CO}_{2}$ in the presence of $\mathrm{H}_{2}$ and CO. Fuel Process Technol 2010;91(8):843-7.

[11] Everson RC, Neomagus HWJP, Kasaini H, Njapha D. Reaction kinetics of pulverized coal-chars derived from inertinite-rich coal discards: gasification with carbon dioxide and steam. Fuel 2006;85(7-8):1076-82.

[12] Bliek A, Lont JC, van Swaaij WPM. Gasification of coal-derived chars in synthesis gas mixtures under intraparticle mass-transfer-controlled conditions. Chem Eng Sci 1986;41(7):1895-909.

[13] Nilsson S, Gómez-Barea A, Ollero P. Gasification of char from dried sewage sludge in fluidized bed: reaction rate in mixtures of $\mathrm{CO}_{2}$ and $\mathrm{H}_{2} \mathrm{O}$. Fuel Sep. 2012.

[14] Tagutchou JP. Gazéification du charbon de plaquettes forêstières: particule isolée et lit fixe continu. Cirad, ED 305. Université de Perpignan; 2008.

[15] Butterman $\mathrm{HC}$, Castaldi $\mathrm{MJ}$. $\mathrm{CO}_{2}$ as a carbon neutral fuel source via enhanced biomass gasification.. Environ Sci Technol 2009;43(23):9030-7.

[16] Bridgeman TG et al. Influence of particle size on the analytical and chemical properties of two energy crops. Fuel 2007;86(1-2):60-72.

[17] Asadullah M, Zhang S, Min Z, Yimsiri P, Li C-Z. Effects of biomass char structure on its gasification reactivity.. Bioresour Technol 2010;101(20):7935-43.

[18] Bonelli PR, Della Rocca PA, Cerrella EG, Cukierman AL. Effect of pyrolysis temperature on composition, surface properties and thermal degradation rates of Brazil Nut shells. Bioresour Technol 2001;76(1):15-22.

[19] Guerrero M, Ruiz MP, Alzueta MU, Bilbao R, Millera A. Pyrolysis of eucalyptus at different heating rates: studies of char characterization and oxidative reactivity. J Anal Appl Pyrol 2005;74(1-2):307-14.

[20] Fu P, Yi W, Bai X, Li Z, Hu S, Xiang J. Effect of temperature on gas composition and char structural features of pyrolyzed agricultural residues. Bioresour Technol 2011;102(17):8211-9.
[21] Yip K, Xu M, Li C-Z, Jiang SP, Wu H. Biochar as a fuel: 3. Mechanistic understanding on biochar thermal annealing at mild temperatures and its effect on biochar reactivity. Energy Fuels 2011;25(1):406-14

[22] Di Blasi C. Modeling chemical and physical processes of wood and biomass pyrolysis. Progr Energy Combust Sci 2008;34(1):47-90.

[23] Vandesteene L, Tagutchou JP, Escudero Sanz FJ, Salvador S. Gasification of woodchip particles: Experimental and numerical study of char- $\mathrm{H}_{2} \mathrm{O}$, char$\mathrm{CO}_{2}$, and char- $\mathrm{O}_{2}$ reactions. Chem Eng Sci 2011;66(20):4499-509.

[24] Lédé J. Biomass pyrolysis: comments on some sources of confusions in the definitions of temperatures and heating rates. Energies 2010;3(4):886-98.

[25] Mermoud F, Salvador S, Vandesteene L, Golfier F. Influence of the pyrolysis heating rate on the steam gasification rate of large wood char particles. Fuel 2006;85(10-11):1473-82.

[26] Ollero P, Serrera A, Arjona R, Alcantarilla $\mathrm{S}$. The $\mathrm{CO}_{2}$ gasification kinetics of olive residue. Biomass Bioenergy 2003;24(2):151-61.

[27] Gómez-Barea A, Ollero P, Fernández-Baco C. Diffusional effects in $\mathrm{CO}_{2}$ gasification experiments with single biomass char particles. 1. Experimental investigation. Energy Fuels 2006;20(5):2202-10.

[28] Mitsuoka K, Hayashi S, Amano H, Kayahara K, Sasaoaka E, Uddin MA Gasification of woody biomass char with $\mathrm{CO}_{2}$ : the catalytic effects of $\mathrm{K}$ and $\mathrm{Ca}$ species on char gasification reactivity. Fuel Process Technol 2011;92(1):26-31.

[29] Huang $\mathrm{Y}$ et al. Effects of metal catalysts on $\mathrm{CO}_{2}$ gasification reactivity of biomass char. Biotechnol Adv 2009;27(5):568-72.

[30] Vamvuka D, Karouki E, Sfakiotakis S. Gasification of waste biomass chars by carbon dioxide via thermogravimetry. Part I: Effect of mineral matter. Fuel 2011;90(3):1120-7.

[31] Yip K, Tian F, Tian F, ichiro Hayashi J, Wu H. Effect of alkali and alkaline earth metallic species on biochar reactivity and syngas compositions during steam gasification. Energy Fuels 2010;24(1):173-81.

[32] Senneca O, Salatino P. A semi-detailed kinetic model of char combustion with consideration of thermal annealing. Proc Combust Inst 2011;33(2):1763-70.

[33] Keown DM, Hayashi J-I, Li C-Z. Drastic changes in biomass char structure and reactivity upon contact with steam. Fuel 2008;87(7):1127-32.

[34] Tay H-L, Kajitani S, Zhang S, Li C-Z. Effects of gasifying agent on the evolution of char structure during the gasification of Victorian brown coal. Fuel 2011.

[35] Zhang S, Min Z, Tay H-L, Wang Y, Dong L, Li C-Z. Changes in char structure during the gasification of mallee wood: effects of particle size and steam supply. Energy Fuels 2012;26(1):193-8.

[36] Barrio M. Experimental investigation of small-scale gasification of biomass. The Norwegian University of Science and Technology; 2002.

[37] Barrio $M$ et al. Steam gasification of wood char and the effect of hydrogen inhibition on the chemical kinetics. In: Bridgwater AV, editor. Progress in themochemical biomass conversion; 2001. p. 32-46.

[38] Liliedahl T, Sjöström K. Modelling of char--gas reaction kinetics. Fuel 1997;76(1):29-37.

[39] Cetin E, Moghtaderi B, Gupta R, Wall TF. Influence of pyrolysis conditions on the structure and gasification reactivity of biomass chars. Fuel 2004;83:2139-50.

[40] Minkova $\mathrm{V}$ et al. Thermochemical treatment of biomass in a flow of steam or in a mixture of steam and carbon dioxide. Fuel Process Technol 2000;62:45-52. 